\title{
Extramedullary Myxopapillary Ependymoma of the Filum Terminale Associated With Syringomyelia: A Case Report
}

\author{
Yavuz Samanci, Suat Erol Celik \\ Neurosurgery Department, Ministry of Health Okmeydani Education and \\ Research Hospital, Istanbul, Turkey
}

\begin{abstract}
Aim: Ependymomas compose the majority of all intradural intramedullary spinal lesions. Filum terminale lesions are rarely associated with syringomyelia. Here we describe a case of extramedullary myxopapillary ependymoma associated with extensive syringomyelia located in the filum terminale.

Material and Methods: A 34-year-old man admitted to our clinic with complaints of bilateral leg weakness, back pain and urinary dysfunction. The magnetic resonance imaging (MRI) of the patient showed us a contrast enhanced intraspinal mass at the level of L2 with a syringomyelia extending from L2 level to Th7 level.

Results: The patient was operated via lumbar laminoplasty and tumor was totally resected.

Conclusion: The removal of tumor is also sufficient for the resolution of syringomyelia and no additional procedure is essential for the treatment of syringomyelia in such cases. This is the first case of extramedullary tumors of the cauda equine with extensive syringomyelia.
\end{abstract}

Key words: Ependymoma, Filum terminale, Syringomyelia.

\section{Introduction and aim of the paper}

Ependymomas compose the majority of all intradural intramedullary spinal lesions and consist $60 \%$ of all glial tumors in spinal cord $(1,2)$. Ependymomas are usually seen in cervical region (44\%), followed by thoracic region (26\%). Intradural intramedullary tumors are commonly related with syringomyelia in the cervicothoracic region and majority of these tumors are glial tumors. Filum terminale lesions are rarely associated with syringomyelia. Here we describe a case of extramedullary myxopapillary ependymoma associated with extensive syringomyelia located in the filum terminale.

\section{Material and methods}

A 34-year-old man was admitted to our hospital with the complaints of bilateral weakness in lower extremities, back pain and urinary dysfunction. The symptoms began three years before the admission and rapidly progressed in the last three months. Neurological examination revealed paraparesis (Grade 3/5) and diminished sensation below the Th 8 level. Deep tendon reflexes were reduced at the right lower extremity while they were increased at the right lower extremity. The anal sphincter tone was also decreased. The MRI of the patient showed us a contrast enhanced intraspinal mass lesion at the level of $\mathrm{L} 2$ with a syringomyelia extending from L 2 level to Th 7 level (Figure 1, Figure 2). 
A laminoplasty from L1 to L3 was performed. When the dura was opened, a dark brown extramedullary tumor $3 \mathrm{~cm}$ in length was encountered. The tumor aroused from the filum terminale and displaced the nerve fibers of cauda equina anteriorly and laterally (Figure 3). The tumor was excised by microsurgical techniques. A thin membranous tissue covering syringomyelic cavity was opened during the tumor removal and slightly xanthochromic cystic fluid was drained.

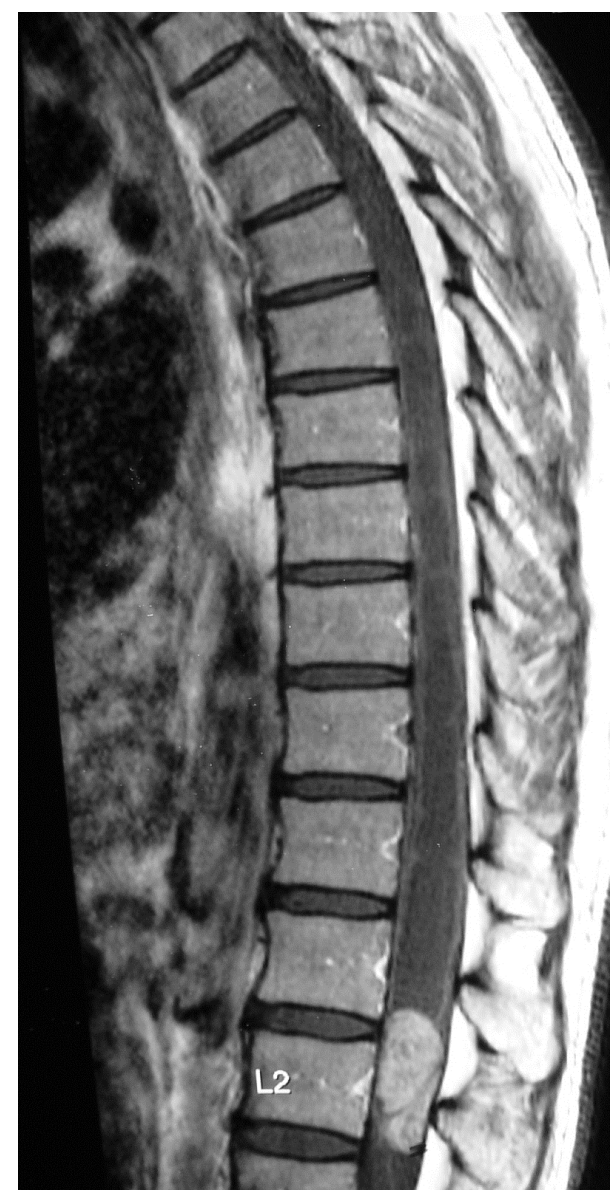

Figure 1

Pre-operative Gadolinium-enhanced, T1-weighted sagittal MRI of the lumbar spine shows an extramedullary tumor with homogeneous enhancement at the L2 level

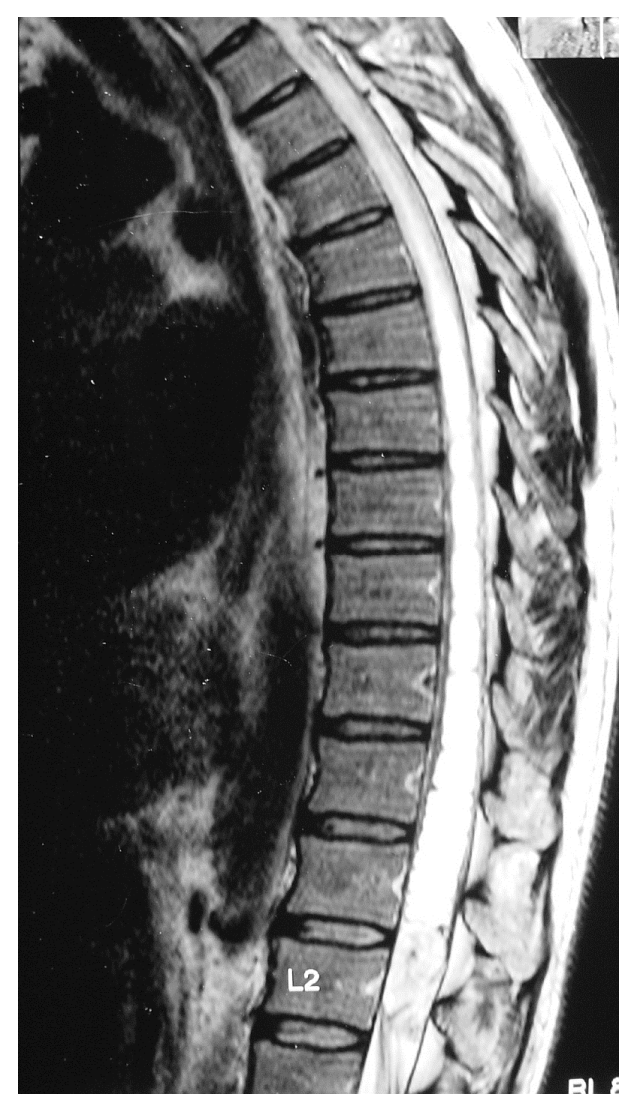

Figure 2

T2-weighted sagittal MRI of the Thoracic spine demonstrates thoracolumbar syringhydromyelia

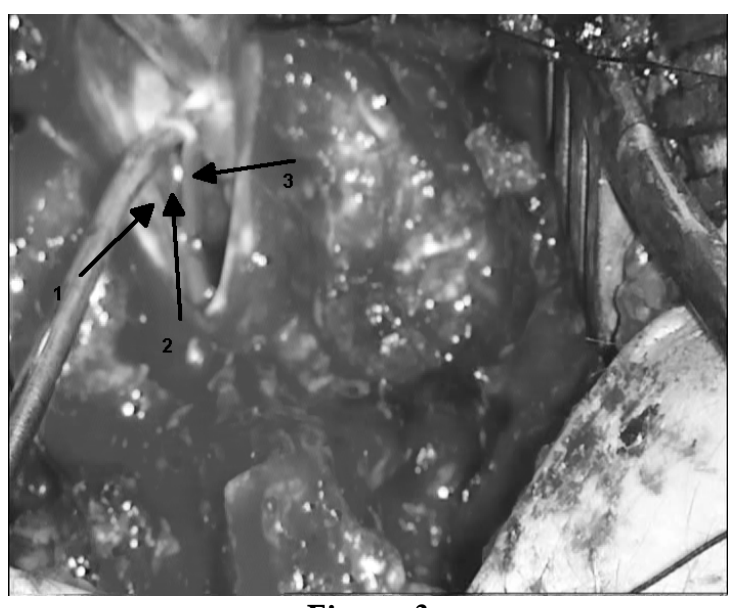

Figure 3

On the left side arrow 1 shows the nerve root, arrow 2 shows the filum and arrow 3 shows the extramedullary ependymoma 
DOI: 10.2478/romneu-2013-0023

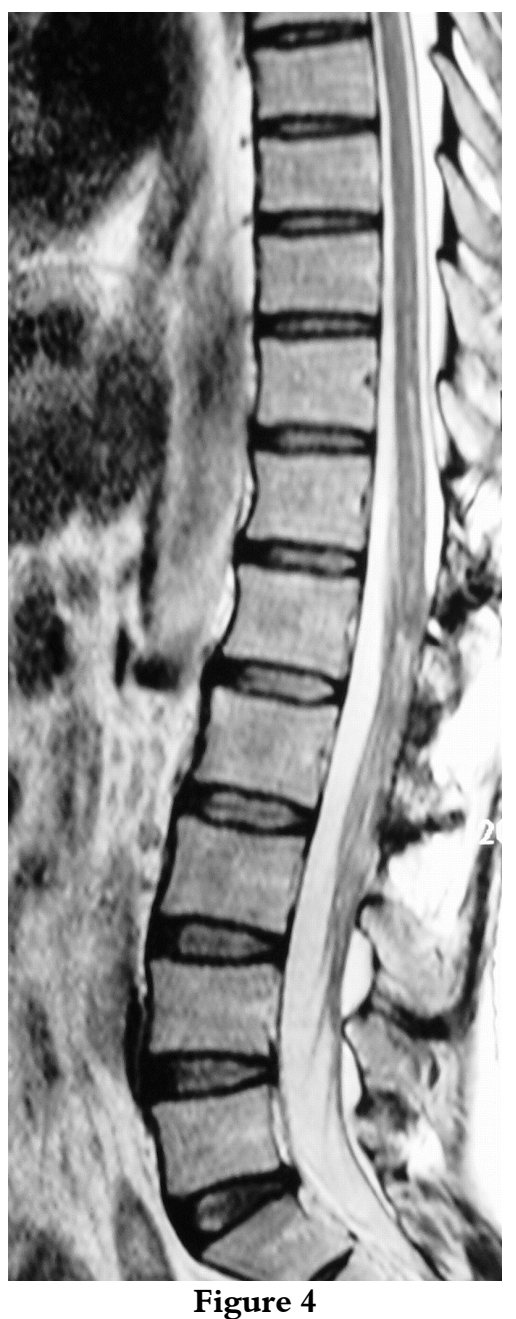

T2-weighted sagittal MRI of thoracolumbar spine shows significant improvement of the syringohydromyelic cavity and total removal of the tumor

\section{Results}

Postoperative course was uneventful and lower extremity weakness of the patient improved (Grade 4/5) immediately. Histopathological examination was reported as "myxopapillary ependymoma". Three years after the operation, the patient was neurologically intact except an intermittent urinary dysfunction. Control MRI revealed total removal of the tumor and disappearance of syringomyelia (Figure 4).

\section{Discussion}

Syringomyelia associated with spinal tumors is common. In most cases, tumors are intramedullary glial tumors located in the cervicothoracic region $(1,3)$. However, the tumors which are located in the distal end of the spinal cord rarely cause syringomyelia (1). Barnett and Rewcastle reviewed seven cases of cauda equina and filum terminale tumors causing syringomyelia including five autopsy cases and two surgical cases (1). Other cases of intramedullary ependymoma of the conus medullaris associated with syringomyelia extending from cervical region were reported by McCormick and Sarikaya et al. $(4,5)$. However, in the case reported by Nagahiro et al. the tumor was an extramedullary epandymoma located in the cauda equina (6). In our case the tumor was purely extramedullary and aroused from the filum terminale. This is the first case of extramedullary tumors of the cauda equina with extensive syringomyelia documented in the MRI era. The pathogenesis of syringomyelia associated with spinal cord tumors is still not well understood. It is usually believed that the effects of tumor including intramedullary softening due to a disturbed blood supply, stasis of the tissue fluid resulting from occlusion of drainage pathways, spread of edema, and hemorrhage into the cord from the tumor are responsible for the development of syringomyelia $(1,6,7)$. However, the reason for the occurrence of syringomyelia associated with the tumors is uncertain. Probably the other entity known to be associated with syringomyelia such as Chiari I malformation, trauma, arachnoiditis, degenerative diseases of the spine, disturbance of the cerebrospinal fluid flow because of obliteration of the 
subarachnoid space play an important role in the development of the syringomyelia. The subarachnoid space and extracellular space of the central nervous system act as a single fluid compartment without any barrier to prevent the fluid movements between them $(7,8)$. However, the removal of tumor is also sufficient for the resolution of syringomyelia and no additional procedure is essential for the treatment of syringomyelia in such cases.

\section{Conclusion}

A unique patient with extramedullary myxopapillary ependymoma located in the filum terminale associated with extensive syringomyelia has been reported. Serial MRI demonstrated the total removal of the lesion and spontaneous resolution of the syringomyelia.

Corresponding author:

Yavuz SAMANCI, M.D.

Neurosurgery Department, Ministry of Health Okmeydani Education and Research Hospital Darulaceze Caddesi No: 25, Okmeydani-Sisli Phone: +90212 2217777 Fax: +90212 2217800, 34384, Istanbul, TURKEY

\section{E-mail:mysamanci@hotmail.com} suatmd@gmail.com

\section{References}

1. Barnett HJM, Rewcastle NB. Syringomyelia and tumours of the nervous system. Barnett HJM, Foster JB, Hudgson P, editors. Major Problems in Neurology, Vol. 1. London: Saunders. 261-300, 1973.

2. Ferry DJ, Hardman JM, Earle KM. Syringomyelia and intramedullary neoplasms. Med Ann Dist Columbia. 38:363-5, 1969.

3. Sloof JL, Kernohan TW, Maccarthy CS. Primary Intramedullary Tumor of the Spinal Cord and Filum Terminale. Philadelphia, Saunders. Pp 180-189, 1964.

4. McCormick PC, Torres R, Post KD. et al. Intramedullary ependymoma of the spinal cord. J Neurosurg. 72:523-32, 1990.

5. Sarikaya S, Acikgoz B, Tekkok IH. et al. Conus ependymoma with holocord syringohydromyelia and syringobulbia. Journal of Clinical Neuroscience 14:901904, 2007.

6. Nagahiro S, Matsukado Y, Kuratsu J. et al. Syringomyelia and syringobulbia associated with an ependymoma of the cauda equina involving the conus medullaris: case report. Neurosurgery. 18:357-60, 1986.

7. Samii M, Klekamp J. Surgical results of 100 intramedullary tumors in relation to accompanying syringomyelia. Neurosurgery. 35:865-73, discussion 73, 1994.

8. Pai SB, Krishna KN. Secondary holocord syringomyelia with spinal hemangioblastoma: a report of two cases. Neurol India. 51:67-8, 2003. 